\title{
UNDERSTANDING THE RELATIONSHIPS BETWEEN RAINFALL AND LUNAR PHASE- A CASE STUDY IN KANDY REGION IN SRI LANKA
}

\author{
N.P.Premachandra ${ }^{1}$, R. P. De Silva ${ }^{1}$ and B.V.R.Punyawardena ${ }^{2}$
}

\begin{abstract}
There is a common belief among Sri Lankans that rainfall always occurs around "Poya day" (the day of full moon). The background for this belief is that the rainfall is influenced by the phase of the moon and this hypothesis was tested using data from Kandy region.

Statistical analyses on this hypothesis were conducted using ephemeris and official rainfall data covering a period of 38 years, from January 1964 to December 2001, for three locations in Kandy region. These analyses were based on four types of comparisons namely, yearly average possibility of rainfall on a moon phase day with that of a control day, yearly average rainfall on a moon phase day with that of a control day, yearly average possibility of rainfall on a moon phase day with that of the opposite moon phase day and yearly average rainfall on a moon phase day with that of the opposite moon phase day. These comparisons were repeated for 'around 3 day period of moon phase day', 'around 5 day period of moon phase day', 'one day before moon phase day + moon phase day', 'two day before moon phase day + moon phase day', 'one day after moon phase day + moon phase day', and 'two day after moon phase day + moon phase day'.
\end{abstract}

As a control sample for the first two types of comparisons, the third day of each month was chosen randomly. Statistical analyses were done using the sign test and the t-test. Using results of the 24 types of comparisons, it was found that no significant correlation between rainfall and the occurrence of the four moon phases. Hence, it can be concluded that the rainfall is not influenced by the phase of the moon. The comment or the belief that 'rainfall always occurs around the "Poya day" may have arisen from people only enriching the myth when raining on "Poya days" during rainy periods, as it is well known, it's probably the heads-I-win, tails-doesn't count approach.

\section{INTRODUCTION}

A common belief among people in almost all countries is that their weather is being influenced by the phase of the moon. For past two centuries, after having collected sufficient amount of meteorological data, scientists have tried to verify this hypothesis. It has often revealed that relationship between phase of the moon and meteorological processes are very weak. However, there are scores of literature on the relationship between rainfall and lunar phase with varying conclusions at different localities. A study for Jakarta in Indonesia has shown that most rain occurs shortly before full moon, and least just after new moon (Linacre and Geerts, 1999). Studies conducted in New Zealand have also shown similar results, i.e. more rainfall at full moon than new moon (Jackson, 1998). An analysis in Magalore on the west coast of India (19011950) revealed that most rain occurs when the moon is in the first quarter and least in the last quarter with a cycle that has small amplitude (Linacre and Geerts, 1999). A study conducted by the National Weather Service in England has shown that about $10 \%$ more rain and occasions of heaviest rain occur in the days following new or full moon (Cole, 1978). Another analysis in North America using rainfall data recorded from 1900-1949 has revealed similar results. It has been found that a significant tendency for the heaviest 24hour rainfalls to occur about 2-3 days after full moon and new moon, and rain was three times as likely to fall in the first and third quarter of the moon than at full or new moon (Ring, 2001). A study using data from 1989 to 1997 of moon phases

${ }^{I}$ Department of Agricultural Engineering, Faculty of Agriculture, University of Peradeniya, Sri Lanka

${ }^{2}$ Natural Resources Management Centre, Department of Agriculture, Peradeniya, Sri Lanka 


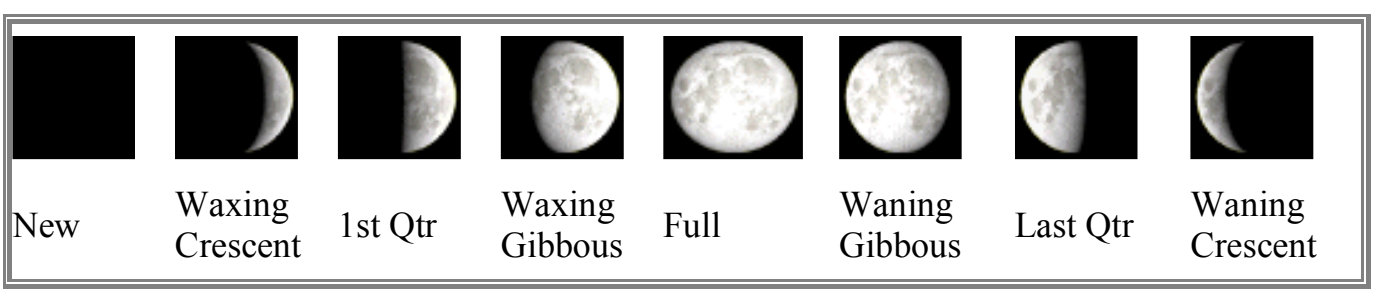

Figure 01: Phases of the moon

and rainfall in Nairne, eastern Adelaide hills, South Australia has shown that rainfall is significantly higher around the 5 day period of the new moon than for the 5 day period of full moon, and the rainfall is at a significantly higher rate around the 5 day period of the new moon, than for the $25 / 26$ day period until the next new moon (Holton, 1998).

Astronomers identify eight different phases of the moon according to its shape. Figure 01 has depicted them in the order of appearance. When the Moon is between the Sun and the Earth, the result is New Moon phase and when the Earth appears between the Moon and the Sun, the result is Full Moon phase. The moon takes about $291 / 2$ days to complete the lunar cycle. So the duration between two opposite moon phases is about $143 / 4$ days.

There are different weather lore accumulated over the centuries in many parts of the world relating appearance of different phases of the moon and prevailing weather. Some of them are "Two moons in a month bring good rains", "If the new moon holds the old moon in her lap, expect fair weather", "Clear moon, frost soon", "A circle around the moon, it will rain or snow soon", "There is a likelihood of higher rainfall around the day of new moon.", "There is a likelihood of lower rainfall around the day of full moon.", "If there are good rains at the time of the new moon, the following month will be wet", and "If there are poor rains at the time of the new moon, the following month will be dry".

A common belief of Sri Lankan people is that "rainfall always occurs around the "Poya day" (the day of full moon). Especially, people in Kandy region believe that there is a relationship between the rainfall and "Kandy Perahera." They believe that rain will occur on the last day of "Randoli Perahera" which is the "Esala" full moon "Poya day" falling in July.

Although, it is the common belief that "Poya days" are likely to give appreciable amount of rains it has never been statistically tested under Sri Lankan conditions. Moreover, literature in other geographical regions has shown that relationships between these two parameters are weak and in some cases it is not consistent from one country to another. Therefore, it is not possible to generalize the observed relationships in other countries for local conditions. Accordingly, the objective of this study was formulated to ascertain whether there is a relationship between the lunar phase and rainfall in Kandy region.

\section{METHODOLOGY}

The hypothesis of the occurrence of rainfall has some relationship with the lunar phase was tested statistically, covering a 38-year period from January 1964 to December 2001, combining ephemeris data and rainfall data from three meteorological locations, namely, Kandy King's Pavilion, Katugastota, and Peradeniya in Kandy region.

The corresponding times and dates of the main four moon phases namely, New, First quarter, Full and Last quarter were obtained from the Lunar Outreach Serviceswebsite(http://www.lunaroutreach .org/phases/phases.dat) and the rainfall data for the same period were obtained from the Natural Resources Management Center, Department of 
Agriculture, Peradeniya, Sri Lanka.In this study, a rainy day and a wet day were identified using two threshold levels as equal or higher than $0.3 \mathrm{~mm}$ of rainfall, and equal or higher than $5.0 \mathrm{~mm}$ rainfall per day, respectively. The analyses were based on four types of comparisons namely, yearly average possibility of a moon phase day to be a rainy day and a wet day with that of a control day, yearly average rainfall on a moon phase day with that of the control day, yearly average possibility of a moon phase day to be a rainy day and a wet day with that of the opposite moon phase day and yearly average rainfall on a moon phase day with that of the opposite moon phase day. These comparisons were repeated for' around 3 day period of moon phase day', 'around 5 day period of moon phase day', 'one day before moon phase day + moon phase day', 'two day before moon phase day + moon phase day', 'one day after moon phase day + moon phase day', and 'two day after moon phase day + moon phase day'.

The 24-hr Greenwich Mean Time was converted to Sri Lankan standard time by adding five and half hours for the dates before 24th May 1996, six and half hours for the dates between 24th May 1996 and 24th October 1996, and six hours for the dates after 24th October 1996. Yearly average possibilities of a moon phase day to be a rainy day were calculated for the four moon phases dividing the number of rainy moon phase days by the number of moon phase days in the year. Yearly average possibilities of a moon phase day to be a wet day were calculated for the four moon phases dividing the number of wet moon phase days by the number of moon phase days in the year. As a control sample for two types of comparisons, the third day of each month was chosen randomly. Statistical analyses were done using the sign test and the t-test.

\section{Statistical Analysis}

Results of statistical analyses are shown here only for the comparison of yearly average possibility of full moon phase day to be a rainy day with relevant values of control day, for Kandy Kings Pavilion rainfall data as an example.

The data are further detailed and summarized in Table 01 representing the average possibilities for each of the 38 years covered by this study. Average possibilities for both the days of the full moon and the control days (third of the month) are listed in columns two and three, respectively. Two statistical tests were applied to the data: the sign test, and the t-test for paired data.

\section{The Sign Test}

One of the simplest statistical tests is based on the hypothesis that if there were no real difference between two sets of data, subtracting one set from the other would yield series of values, half of which would be positive and half negative. Naturally, one should not expect the signs to be distributed exactly half and half, but the distribution should not depart too far from the ideal. As a rule of thumb for 40 sets of data, if two populations are truly the same the probability is less than 5 percent for one sign to occur as few as 13 times. For our 38 years, the lesser occurring sign (positive when subtracting the control day average possibility from the full moon day average possibility) occurs fourteen times-a not unlikely probability of occurrence if the two populations are the same. A more definitive sign test based on the $\chi^{2}$ distribution can be applied.

$\sum \frac{(\mathrm{O}-\mathrm{E})^{2}}{\mathrm{E}}$

Where $E$ is the expected number of plus (and of minus) signs and $\mathrm{O}$ is the observed number of signs. For the data in Table 01,

$$
\frac{(14-17.5)^{2}+(21-17.5)^{2}}{17.5}=1.4
$$

The value calculated by the above formula must be greater than 3.841 to say, with 95 percent confidence, that the two sets of 
Table 01. A comparison of average possibility to be a rainy day of the full moon phase day to the third of the month for Kandy Kings Pavilion rainfall data

\begin{tabular}{|c|c|c|c|}
\hline \multirow[b]{2}{*}{ Year } & \multicolumn{2}{|c|}{ Average possibility } & \multirow[b]{2}{*}{$\begin{array}{r}\text { Full moon } \\
\text { minus control }\end{array}$} \\
\hline & $\begin{array}{c}\text { Full } \\
\text { moon }\end{array}$ & $\begin{array}{c}\text { Control } \\
\text { day }\end{array}$ & \\
\hline 1964 & 0.2500 & 0.4167 & -0.1667 \\
\hline 1965 & 0.5000 & 0.4167 & 0.0833 \\
\hline 1966 & 0.5385 & 0.4167 & 0.1218 \\
\hline 1967 & 0.4167 & 0.5833 & -0.1667 \\
\hline 1968 & 0.4167 & 0.3333 & 0.0833 \\
\hline 1969 & 0.2308 & 0.4167 & -0.1859 \\
\hline 1970 & 0.5833 & 0.5000 & 0.0833 \\
\hline 1971 & 0.1667 & 0.2500 & -0.0833 \\
\hline 1972 & 0.3077 & 0.3333 & -0.0256 \\
\hline 1973 & 0.1667 & 0.3333 & -0.1667 \\
\hline 1974 & 0.3846 & 0.1667 & 0.2179 \\
\hline 1975 & 0.5000 & 0.5833 & -0.0833 \\
\hline 1976 & 0.3333 & 0.4167 & -0.0833 \\
\hline 1977 & 0.5385 & 0.4167 & 0.1218 \\
\hline 1978 & 0.5000 & 0.3333 & 0.1667 \\
\hline 1979 & 0.1667 & 0.4167 & -0.2500 \\
\hline 1980 & 0.2308 & 0.2500 & -0.0192 \\
\hline 1981 & 0.2500 & 0.3333 & -0.0833 \\
\hline 1982 & 0.4615 & 0.2500 & 0.2115 \\
\hline 1983 & 0.4167 & 0.0833 & 0.3333 \\
\hline 1984 & 0.6667 & 0.3333 & 0.3333 \\
\hline 1985 & 0.2308 & 0.5000 & -0.2692 \\
\hline 1986 & 0.3333 & 0.2500 & 0.0833 \\
\hline 1987 & 0.1667 & 0.1667 & 0.0000 \\
\hline 1988 & 0.3077 & 0.3333 & -0.0256 \\
\hline 1989 & 0.6667 & 0.5000 & 0.1667 \\
\hline 1990 & 0.3333 & 0.4167 & -0.0833 \\
\hline 1991 & 0.3077 & 0.5000 & -0.1923 \\
\hline 1992 & 0.4167 & 0.5000 & -0.0833 \\
\hline 1993 & 0.6154 & 0.5000 & 0.1154 \\
\hline 1994 & 0.1667 & 0.3333 & -0.1667 \\
\hline 1995 & 0.4167 & 0.4167 & 0.0000 \\
\hline 1996 & 0.3077 & 0.1667 & 0.1410 \\
\hline 1997 & 0.5000 & 0.5000 & 0.0000 \\
\hline 1998 & 0.1667 & 0.3333 & -0.1667 \\
\hline 1999 & 0.3846 & 0.5833 & -0.1987 \\
\hline 2000 & 0.3333 & 0.5000 & -0.1667 \\
\hline 2001 & 0.3077 & 0.5833 & -0.2756 \\
\hline Mean: & 0.3681 & 0.3860 & -0.0179 \\
\hline SD: & 0.1457 & 0.1277 & 0.1628 \\
\hline
\end{tabular}


data are not the same. Because our calculated value is less than 3.841, we should accept the null hypothesis: we have not shown the two sets of data to be different statistically.

\section{t-test for paired data}

This second test is based on the assumption that if two sets of paired data are the same then the average of the differences between the pairs should be zero. Our data consist of 38 pairs: one pair for each year studied. As with the sign test described above, for each year the average possibility to be a rainy day for the control day was subtracted from the average possibility to be a rainy day for the moon phase day. An average and standard deviation were then calculated for these differences. The results are listed in the Table 01 at the bottom of the fourth column.

If the hypothesis is true that the average possibility to be a rainy day for the moon phase day is higher than that on the control day, the average of the differences between the two sets of data must be significantly higher than zero. The greater the departure from zero, the greater the probability that to be a rainy day for moon phase day.

$$
\mathrm{t}=\frac{\mathrm{d}}{\mathrm{s} / \sqrt{\mathrm{n}}}
$$

where $\mathrm{d}$ is the mean difference between the two sets of data, $s$ is the standard deviation on the differences, and $\mathrm{n}$ is the number of data pairs.

$$
\begin{aligned}
& \mathrm{t}=\frac{-0.0179}{0.1628 / \sqrt{38}} \\
& \mathrm{t}=-0.677
\end{aligned}
$$

If the calculated value is higher than 1.697 we may, with 95 percent confidence, reject the null hypothesis. As our calculated value, however, is not higher than 1.697, we should accept the null hypothesis: the difference between the pairs has not been shown to be significantly different from zero.

Table 02. A comparison of average possibility to be a rainy day of the full moon phase day to the third of the month for Kandy Kings Pavilion rainfall data

\begin{tabular}{lcc}
\hline Hypothesis & $\begin{array}{c}\text { Number of } \\
\text { comparisons }\end{array}$ & $\begin{array}{c}\text { Number of } \\
\text { rejection the null } \\
\text { hypothesis }\end{array}$ \\
\hline $\begin{array}{l}\text { Higher possibility to be rainy days on moon phase } \\
\text { days }\end{array}$ & 84 & 2 \\
$\begin{array}{l}\text { Higher possibility to be wet days on moon phase } \\
\text { days }\end{array}$ & 84 & 0 \\
$\begin{array}{l}\text { Higher possibility to be rainy days on moon phase } \\
\text { days than the opposite moon phase days }\end{array}$ & 84 & 0 \\
$\begin{array}{l}\text { Higher possibility to be wet days on moon phase } \\
\text { days than the opposite moon phase days }\end{array}$ & 84 & 0 \\
$\begin{array}{l}\text { Higher rainfall on moon phase days } \\
\begin{array}{l}\text { Higher rainfall on moon phase days than the } \\
\text { opposite moon phase days }\end{array}\end{array}$ & 84 & 0 \\
\hline
\end{tabular}




\section{DISCUSSION}

The signed test based on $\chi^{2}$ distribution checks that the two sets of data are not the same, and the right tail $\mathrm{t}$ - test for paired data checks that the first data set is higher than the second. If only the sign test based on $\chi^{2}$ distribution rejects the null hypothesis, and the t-test for paired data accepts the null hypothesis, the first data set may be less than the second with 95 percent confidence interval. If only the ttest rejects the null hypothesis, and the sign test based on $\chi^{2}$ distribution accepts the null hypothesis, the data may not have distributed normally. So if the two tests reject the null hypothesis with 95 percent confidence interval, the hypothesis that first data set is higher than the second, can be accepted with 95 percent confidence interval.

The total number of comparisons is 504 , because there are 7 considering periods, 4 moon phases, 3 locations and 6 hypotheses. From them there are only two cases where the null hypotheses are rejected by both tests (Table 02 ). They are,

1. The comparison of average possibility to be a rainy day, for 'one day before the first quarter phase day and first
2. quarter phase day', with the $2^{\text {nd }}$ and $3^{\text {rd }}$ days of the months, for Kandy Kings Pavilion rainfall data, and

3. The comparison of average possibility to be a rainy day, for 'one day after the first quarter phase day and first quarter phase day', with the $3^{\text {rd }}$ and $4^{\text {th }}$ days of the months, for Peradeniya rainfall data.

Therefore, the results of this study do not support an existence of a relationship between the lunar phase and the rainfall for the region.

\section{CONCLUSIONS}

The statistical analyses of 38 years of data from three locations in Kandy region indicate no relationship between the lunar phase and the rainfall. The common belief that 'rainfall always occurs on or around Poya day' may have arisen from people due to the biased noticing of the weather on full moon days than the other days. This is probably because people walk out to religious places (temples) on full moon days, and feels the weather conditions more than they do on a normal day.

\section{REFERENCES}

Cole, H. (1978). The Moon and Weather Article No. 259. http://www.gi.alaska.edu/ScienceForum/ASF2/259.html

Holton, I. (1998). Does the moon affect rainfall? http://users.senet.com.au/ holton7/articlemoon

Jackson, J. (1998). Lunar Lore. http://www.conservation.state.mo.us/conmag/1998/11/5.html

Linacre, E. and B. Geerts. (1999). Rainfall, temperature and lunar phase. http://www-das.uwyo.edu/ geerts/cwx/notes/chap10/moon.html

Ring, K. (2001). Weather ezine \# 041. http://www.ace-net.com.au/ carls/ezines/ezine041.html 